\title{
The temperament and character personality profile of the glaucoma patient
}

\author{
Harun Çakmak ${ }^{1 *}$, Vesile Altinyazar², Suzan Güven Yilmaz ${ }^{4}$, Imran Kurt Ömürlü${ }^{3}$, Tolga Kocatürk' ${ }^{1}$ Alper Yazici ${ }^{5}$, \\ Cumali Değirmenci ${ }^{4}$, Sema Oruç Dündar ${ }^{1}$ and Halil Ates ${ }^{4}$
}

\begin{abstract}
Background: To determine the temperament and character profile of glaucoma patients.

Methods: A total of 234 patients (104 with primary open angle glaucoma, and 130 control subjects without any ocular disease) were selected for this prospective, cross-sectional study. All the participants underwent a comprehensive ophthalmological examination, including the best corrected visual acuity, intraocular pressure measurement, gonioscopy, and visual field analysis. All the participants were given the Turkish version of the Temperament and Character Inventory $(\mathrm{TCl})$. The $\mathrm{TCl}$ is a self-reported evaluate, with 240 true/false items measuring four domains of temperament; harm avoidance (HA), persistence (PS), novelty seeking (NS), reward dependence (RD), and three domains of character; self-transcendence (ST), cooperativeness (C), self-directedness (SD).

Results: The glaucoma patients achieved the higher scores than the controls for the HA and SD dimensions $(p<0.001$ and $p=0.033)$. The glaucoma patients scored lower than the controls for the NS, P and ST dimensions $(p<0.001, p<0.001$ and $p=0.002)$. There were no differences in the RD and $C$ scores between the patients and the controls ( $p=0.944$ and $p=0.343$ ). There was no correlation between the duration of illness and the TCl dimensions. Disease severity was positively associated with $\mathrm{HA}(r=0,220, p=0,025)$ and the anticipatory worry $(r=0.227, p=0.021)$ dimension.
\end{abstract}

Conclusions: Glaucoma patients had a different personality profile to healthy individuals. This may affect treatment compliance and is also important when coping with maladaptive patient attitudes.

Keywords: Glaucoma, Temperament and Character inventory, Personality profile

\section{Background}

Glaucoma is characterized by progressive optic nerve damage, which is one of the most frequent cause of irreversible visual damage and blindness in the industrialized world [1]. Stress is considered as a risk factor for glaucoma, and is reported as increasing the intraocular pressure (IOP) both in healthy subjects and glaucoma patients [2, 3]. In previous studies, the importance of personality structure has proven the perception that there is a maintenance of high levels of stress in glaucoma patients $[4,5]$. The differences in personality structure of glaucoma patients; excitable temperament, perfectionistic pattern, neuroticism, hypochondriacal tendencies, irritability, anxiety traits, and type A behavioral

\footnotetext{
* Correspondence: dharuncakmak@gmail.com

'Department of Ophthalmology, Adnan Menderes University Medical Faculty, Merkez Kampus Kepez Mevkii, 09100 Aytepe, Aydın, Turkey

Full list of author information is available at the end of the article

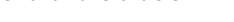

pattern introversion are the issues which have been reported on for a long time [6-13]. In some studies, these personality patterns were reported to affect adherence to treatment, and some have been reported to be a risk factor in the development of glaucoma $[9,13]$. However, personality was not measured by the validity criteria, and a consistent personality profile of glaucoma patients has yet to be established.

According to Cloninger's psychobiological model, the dimensional approach has some advantages when studying personality [14]. Personality has been proposed as two separate elements i.e. temperament and character. Temperament is proposed as the underlying biological and genetic structural component of the personality, and refers to the automatic emotional response to incidents; while character involves self-conception, and is affected by life experiences, which provide diversity in the values

( Biomed Central 
of individual choice [15]. According to this model, temperament is proposed as being dividing into four different independent dimensions; Novelty Seeking (NS) is the orientation towards innovation and reward. Harm Avoidance (HA) is the tendency to inhibit behavior in response to unrewarded situations, and to avoid potential punishment. Reward Dependence (RD) is the tendency to maintain behavior to be socially rewarded. Persistence (PS) is the continuation of the certain behavior in spite of the intermittent reward and frustration. Character is divided into three different dimensions; Self-directedness (SD) is the perception of the self as an autonomous individual. Cooperativeness $(C)$ is the perception of the self as a part of society, and positive relationships with others. Self-transcendence (ST) is as part of the self-perception of the universe.

To our knowledge the Temperament and Character Inventory-240 (TCI-240), with a personality test that has shown a good genetic link, has not been used with glaucoma patients. The aim of this study was to investigate whether there was a different personality structure in glaucoma patients when compared to healthy subjects. For if such different personality structure was found to be associated with the parameters of the disease, then the treatment was to address that influence. Thus, it might be possible for a psychological intervention to be used for improving the treatment of glaucoma.

\section{Methods}

A total of 234 patients (104 with primary open angle glaucoma [POAG], and 130 control subjects without any ocular disease) were enrolled on this prospective, cross-sectional study. All the participants underwent a comprehensive ophthalmological examination, including best corrected visual acuity, the IOP measurement with a Goldman applanation tonometer, a gonioscopy, visual fields using with the Humphrey D (Humphrey Systems Field Analyzer Model II 750, Zeiss, USA) the 24-2 Swedish Interactive Thresholding Algorithm I (Standard 24-2 VF tests; SITA-SAP, Carl Zeiss Meditec, Inc.) standard program, and a detailed fundus examination. The patients with unreliable visual fields or additional ocular abnormalities were excluded from the study.

The ethics approval for this prospective study was obtained from the Adnan Menderes University local research ethics committee. Written informed consent for participation in the study was obtained from each patient.

The participants with IOP $<21 \mathrm{mmHg}$, normal visual fields (VF), normal optic discs, open angles on gonioscopy and no suspicion of any form of glaucoma or eye disease were placed in the control group. We determined the severity of the glaucoma according to the Hodapp-Anderson-Parrish (HAP) grading system in the study group [16]. Early glaucomatous loss was determined when less than 10 points below the $\mathrm{p}<1 \%$ level, less than 18 points depressed below the $5 \%$ probability level, no point in the central 5 degrees with a sensitivity of fewer than $15 \mathrm{~dB}$, and $\mathrm{MD}$ higher than $-6 \mathrm{~dB}$; moderate glaucomatous loss was determined when less than 20 points below the $\mathrm{p}<1 \%$ level, less than 37 points depressed below the $5 \%$ probability level, the MD is between -6 to $-12 \mathrm{~dB}$, no absolute defect $(0 \mathrm{~dB})$ in the central 5 degrees, only one hemifield with the sensitivity of $<15 \mathrm{~dB}$ in the central 5 degrees, and the advanced glaucomatous loss was determined when more than 20 points below the $p<1 \%$ level, more than 37 points depressed below the $5 \%$ probability level, an MD higher than $-12 \mathrm{~dB}$, absolute deficit $(0 \mathrm{~dB})$ in the central 5 degrees, and sensitivity less than $15 \mathrm{~dB}$ in the central 5 degrees in both hemifields.

Patients compliance to their medication regimen was assessed. Compliance was considered as following the regimen on a daily basis over the past 2 or 3 months. High treatment compliance was defined as missing installation not more than once a week. Poor treatment compliance was defined as missing at least two drop of medication per week and or the inability to accurately describe one's own medication regimen.

All participants were given the Turkish version of the TCI for evaluating personality $[17,18]$. The TCI is a selfreported evaluate with 240 true/false items measuring four domains of temperament; Harm avoidance (HA) includes anticipatory worry (HA1), fear of uncertainty (HA2), shyness (HA3) and fatigability (HA4). Reward Dependence (RD) includes sentimentality (RD1), openness to friendly communication (RD2), attachment (RD3), and dependence (RD4). Novelty Seeking (NS) is contain exploratory excitability (NS1), impulsiveness (NS2), extravagance (NS3) and disorderliness (NS4). Persistence (PS) is also included in the temperament dimensions.

The three domains of character are: self-directedness (SD), cooperativeness (C), and self-transcendence (ST). SD includes responsibility (SD1), purposeful (SD2), resourcefulness (SD3), self-acceptance (SD4), and congruence (SD5). C consists of social acceptance (C1), empathy (C2), helpfulness (C3), compassion (C4), pure-hearted conscience (C5), and ST includes self-forgetful (ST1), transpersonal identification (ST2), and spiritual acceptance (ST3).

The suitability for a normal distribution of quantitative data was analyzed by using the Kolmogorov-Smirnov test. The test was used for the intergroup comparison of variables, which are suitable for normal distribution, and the descriptive statistics were shown as the mean \pm standard deviation form. The Intergroup comparison of the variables that were not suitable for a normal distribution was carried out with the Mann Witney U test, and the descriptive statistics were shown as the median (25-75 percentiles) form. The Chi-square test was used for the comparison of the qualitative data. The Spearman correlation analysis was 
used for the relationship between variables. When the $p$ value was $<0.05$, it was considered as statistically significant.

\section{Results}

In the glaucoma group, there were 54 male patients and 50 female patients, while the control group consisted of 67 male patients and 63 female patients. The mean age was $59.36 \pm 10.38$ years and $57.34 \pm 8.27$ years in the glaucoma and control groups respectively. There was no difference between the demographic variables of the two groups (Table 1).

The duration of the glaucoma was $61.17 \pm 46.47$ months in the study group. Seventy nine $(76 \%)$ patients had high treatment compliance, and $25(24 \%)$ patients had poor treatment compliance. Twenty six glaucoma patients $(25 \%)$ had undergone previous glaucoma surgery. The details of the ophthalmic examination results in the glaucoma patients are shown in Table 2.

The mean scores regarding the TCI dimensions among the glaucoma patients and the control subjects are shown in Table 3.

The glaucoma patients had significantly lower scores than the controls on NS and also on the two NS dimensions: NS3 and NS4. The patients with glaucoma had higher scores than the controls HA $(p<0.001)$ and the three HA dimensions; HA1, HA2 and HA3 $(p=0.048, p<0.001$ and $p<0.001)$. There was no difference according to the RD and $\mathrm{C}$ scores between the groups $(p=0.944$ and $p=0.343)$. PS was significantly lower in the glaucoma patients than in the control subjects $(p<0.001)$. The glaucoma patients had significantly higher scores than the controls in SD $(p=0.033)$ and one SD dimension: SD5 $(p=0.008)$. The

Table 1 Sociodemographic characteristics of glaucoma patients and control subjects

\begin{tabular}{|c|c|c|c|}
\hline & Glaucoma $(n=104)$ & Control $(n=130)$ & $p$ \\
\hline Age (Mean \pm SD) & $59.36 \pm 10.38$ & $57.34 \pm 8.27$ & 0.124 \\
\hline Gender & & & 0.347 \\
\hline Male & 50 (48.1\%) & 67 (51.5\%) & \\
\hline Female & $54(51.9 \%)$ & $63(48.5 \%)$ & \\
\hline Education & & & 0.337 \\
\hline Primary education & $58(55.8 \%)$ & 68 (52.3\%) & \\
\hline Secondary education & $29(27.9 \%)$ & $32(24.6 \%)$ & \\
\hline High school & $17(16.3 \%)$ & 30 (23.1\%) & \\
\hline Live & & & 0.176 \\
\hline Village or Town & 20 (19.2\%) & $17(13.1 \%)$ & \\
\hline City & $84(80.8 \%)$ & $113(86.9 \%)$ & \\
\hline Living situation & & & 0.676 \\
\hline Living alone & $14(12.3 \%)$ & 18 (13.8\%) & \\
\hline Living with a partner & $100(87.7 \%)$ & $112(86.2 \%)$ & \\
\hline
\end{tabular}

Table 2 Details of ophthalmic examination results in glaucoma patients

\begin{tabular}{ll}
\hline BCVA OD & $0.81 \pm 0.27$ \\
BCVA OS & $0.79 \pm 0.30$ \\
Duration of illness (month) & $61.17 \pm 46.47$ \\
Glaucoma severity & \\
• Early glaucomatous loss & $40(38.5 \%)$ \\
• Moderate glaucomatous loss & $48(46.1 \%)$ \\
- Advance glaucomatous loss & $16(15.4 \%)$ \\
Previous glaucoma surgery & $26(25 \%)$ \\
Treatment compliance & \\
• High & $79(76 \%)$ \\
• Poor & $25(24 \%)$ \\
Antiglaucoma medication & \\
• One box & $34(32.7 \%)$ \\
• Two boxes & $30(28.8 \%)$ \\
• Three boxes & $31(29.8 \%)$ \\
• No medication & $9(8.7 \%)$ \\
\hline
\end{tabular}

patients with glaucoma had significantly lower scores than the controls in ST $(p=0.02)$ and one ST dimension: ST3 $(p<0.001)$. There was no statistical difference in the TCI according to the gender in the groups.

The correlations between the TCI dimensions and the duration of the illness, the treatment response, the disease severity, the adherence to glaucoma medication, and previous glaucoma surgery among the glaucoma patients are shown in Table 4.

There was no correlation between the duration of the illness and the TCI dimensions. The disease severity was negatively associated with NS1 $(r=-0,197, p=0,045)$ and positively associated with HA1 $(r=0.227, p=0.021)$ and HA $(r=0,220, p=0,025)$. The treatment response was associated with the C4 $(r=0,226, p=0,021)$ and ST2 $(r=0,258$, $p=0,008)$ dimensions. There were associations between the previous glaucoma surgery and seven TCI dimensions also; HA2 $(r=-0.220, p=0.025)$, RD1 $(r=-0.254, p=0.009)$, $\mathrm{RD}(r=-0.244, p=0.013), \mathrm{P}(r=-0.222, p=0.023)$, SD3 $(r=0.247, p=0.011), \mathrm{C} 2(r=0.301, p=0.002)$ and C4 $(r=-0.203, p=0.039)$.

\section{Discussion}

This study showed that the glaucoma patients have a characteristic personality profile with their lower scores for the NS, P, ST, and higher scores for the HA and SD dimensions when compared to the controls. Temperament is described as a heritable individual difference, and in particular, HA is viewed as a heritable bias in anxiety, which is evidenced by anticipatory worry, shyness, and increased fatigability, all in response to signals of punishment. The disease severity was positively associated with the HA and HA1 dimension as 
Table 3 Mean scores on TCl dimensions among glaucoma patients and control subjects

\begin{tabular}{|c|c|c|c|}
\hline & Glaucoma $(n=104)$ & Control $(n=130)$ & $P$ \\
\hline Exploratory excitability (NS1) & $5(4-6)$ & $6(4-7)$ & 0,200 \\
\hline Impulsiveness (NS2) & $4(3-5)$ & $4(3-5)$ & 0,554 \\
\hline Extravagance (NS3) & $3(2-4)$ & $5(3-6)$ & $<0,001$ \\
\hline Disorderliness (NS4) & $3(2-5)$ & $4(3-5)$ & 0,006 \\
\hline Total Novelty seeking (NS) score & $16(14-19)$ & $18(16-21)$ & $<0,001$ \\
\hline Anticipatory worry (HA1) & $6(4-7)$ & $5(4-6)$ & 0,048 \\
\hline Fear of uncertainty (HA2) & $5(4-6)$ & $4(3-5)$ & $<0,001$ \\
\hline Shyness (HA3) & $4(3-6)$ & $3(2-4)$ & $<0,001$ \\
\hline Fatigability (HA4) & $4(3-6)$ & $4(3-6)$ & 0,259 \\
\hline Total Harm avoidance (HA) score & $19(17-22)$ & $17(14-19)$ & $<0,001$ \\
\hline Sentimentality (RD1) & $7(5-8)$ & $7(6-8)$ & 0,280 \\
\hline Openness to warm communication (RD2) & $4(3-6)$ & $4(3-6)$ & 0.259 \\
\hline Attachment (RD3) & $4(3-5)$ & $4(3-5)$ & 0,762 \\
\hline Dependence (RD4) & $2(2-4)$ & $3(2-4)$ & 0,166 \\
\hline Total Reward dependence (RD) score & $13(12-15)$ & $13(11-15)$ & 0,944 \\
\hline Persistence & $5(3,25-5,75)$ & $6(4-7)$ & $<0,001$ \\
\hline Responsibility (SD1) & $5(3-6)$ & $4(3-5)$ & 0,392 \\
\hline Purposeful (SD2) & $5(4-6)$ & $5(4-7)$ & 0,795 \\
\hline Resourcefulness (SD3) & $3(2,25-4)$ & $3(2-4)$ & 0,617 \\
\hline Self-acceptance (SD4) & $6(5-7)$ & $5(4-7)$ & 0,116 \\
\hline Congruence (SD5) & $8(7-10)$ & $8(6-9)$ & 0,008 \\
\hline Total Self-directedness (SD) score & $27(24-30)$ & $25(23-29)$ & 0,033 \\
\hline Social acceptance (C1) & $5(4-6)$ & $6(5-6)$ & 0,026 \\
\hline Empathy (C2) & $4(2-4)$ & $4(3-5)$ & 0,014 \\
\hline Helpfulness (C3) & $4(3-5)$ & $4(3,25-5)$ & 0,925 \\
\hline Compassion (C4) & $8(6-9)$ & $7(6-9)$ & 0,413 \\
\hline Pure-hearted conscience (C5) & $6(5-7)$ & $6(5-7)$ & 0,168 \\
\hline Total Cooperativeness (C) score & $26(23-28)$ & $26,5(24-30)$ & 0,343 \\
\hline Self-forgetful (ST1) & $6(4-7)$ & $6(5-7)$ & 0,286 \\
\hline Transpersonal identification (ST2) & $5(4-7)$ & $6(5-7)$ & 0,054 \\
\hline Spiritual acceptance (ST3) & $6(5-7)$ & $7(5,25-9)$ & $<0,001$ \\
\hline Total Self-transcendence (ST) score & $17(15-19)$ & $19(16-22)$ & 0,002 \\
\hline
\end{tabular}

well as the higher scores in the HA in the glaucoma patients than in the controls. Neuroticism is expressed as subscales of the Neuroticism Extraversion Openness FiveFactor Inventory (NEO-FFI) developed by Eysenck, and designed to measure how the subject can cope with, and beat stress as in HA [19]. High HA scores were found to show a strong correlation with high Neuroticism scores [20]. High neuroticism scores are the most consistent findings in glaucoma patients in studies investigating personality in glaucoma [4, 21, 22].Recently, Bubella et al. [13] investigated the type A personality type, which is a more stress-sensitive trait, and they found that type A behavior is much more evident in glaucoma patients.
They demonstrated that patients with type A behavior have more fluctuations in the daily tonometric curve, which could be the cause of the more evident field defects [13]. Our findings suggested that higher HA personality features may be associated with glaucoma in accordance with the publications such as higher neuroticism and type A behavior, and also may create a predisposition for glaucoma. These personality features are associated with emotional instability that have been associated with dysregulated intraocular pressure in several studies [13, 23]. Trying to improve the emotional instability may lead to important implications for the long-term therapeutic approach to glaucoma. 
Table 4 Associations between TCl and duration of illness, disease severity, previous glaucoma surgery, treatment response in glaucoma patients

\begin{tabular}{|c|c|c|c|c|c|}
\hline & & Duration of illness & Disease severity & Previous glaucoma surgery & Treatment response \\
\hline \multirow[t]{2}{*}{ NS1 } & r & 0,071 & $-0,197$ & 0.096 & $-0,003$ \\
\hline & $p$ & 0,472 & 0,045 & 0.334 & 0,979 \\
\hline \multirow[t]{2}{*}{ NS2 } & r & 0,113 & $-0,029$ & 0.094 & 0,046 \\
\hline & $p$ & 0,254 & 0,773 & 0.341 & 0,643 \\
\hline \multirow[t]{2}{*}{ NS3 } & r & 0,036 & $-0,028$ & -0.084 & 0,075 \\
\hline & $p$ & 0,716 & 0,780 & 0.395 & 0,451 \\
\hline \multirow[t]{2}{*}{ NS4 } & r & 0,041 & 0,056 & 0.055 & $-0,019$ \\
\hline & $p$ & 0,679 & 0,576 & 0.577 & 0,850 \\
\hline \multirow[t]{2}{*}{ NS Total } & r & 0,160 & $-0,105$ & 0.079 & 0,058 \\
\hline & $p$ & 0,106 & 0,288 & 0.425 & 0,560 \\
\hline \multirow[t]{2}{*}{ HA1 } & r & $-0,086$ & 0,227 & -0.089 & 0,190 \\
\hline & $p$ & 0,383 & 0,021 & 0.368 & 0,054 \\
\hline \multirow[t]{2}{*}{ HA2 } & r & $-0,128$ & 0,056 & -0.220 & 0,147 \\
\hline & $p$ & 0,194 & 0,576 & 0.025 & 0,137 \\
\hline \multirow[t]{2}{*}{ HA3 } & $r$ & 0,078 & 0,057 & -.163 & $-0,028$ \\
\hline & $p$ & 0,432 & 0,567 & 0.097 & 0,778 \\
\hline \multirow[t]{2}{*}{ HA4 } & r & $-0,047$ & 0,083 & 0.140 & $-0,037$ \\
\hline & $\mathrm{p}$ & 0,633 & 0,403 & 0.156 & 0,712 \\
\hline \multirow[t]{2}{*}{ HA Total } & $r$ & $-0,080$ & 0,220 & -0.084 & 0,097 \\
\hline & $p$ & 0,419 & 0,025 & 0.395 & 0,328 \\
\hline \multirow[t]{2}{*}{ RD1 } & $r$ & $-0,189$ & 0,012 & -0.254 & 0,127 \\
\hline & $\mathrm{p}$ & 0,055 & 0,906 & 0.009 & 0,199 \\
\hline \multirow[t]{2}{*}{ RD2 } & $r$ & $-0,165$ & 0,056 & -0.254 & 0,055 \\
\hline & $p$ & -0.143 & 0,854 & 0.234 & 0,188 \\
\hline \multirow[t]{2}{*}{ RD3 } & r & 0,062 & $-0,025$ & -0.133 & 0,036 \\
\hline & $\mathrm{p}$ & 0,531 & 0,802 & 0.177 & 0,720 \\
\hline \multirow[t]{2}{*}{ RD4 } & $r$ & 0,043 & 0,017 & 0.099 & 0,067 \\
\hline & $p$ & 0,668 & 0,860 & 0.319 & 0,498 \\
\hline \multirow[t]{2}{*}{ RD Total } & $r$ & $-0,084$ & $-0,021$ & -0.244 & 0,145 \\
\hline & $p$ & 0,394 & 0,835 & 0.013 & 0,141 \\
\hline \multirow[t]{2}{*}{$P$} & r & $-0,027$ & 0,076 & -0.222 & 0,187 \\
\hline & $p$ & 0,785 & 0,441 & 0.023 & 0,057 \\
\hline \multirow[t]{2}{*}{ SD1 } & r & $-0,046$ & 0,005 & 0.072 & $-0,052$ \\
\hline & $p$ & 0,646 & 0,960 & 0.470 & 0,597 \\
\hline \multirow[t]{2}{*}{ SD2 } & r & $-0,156$ & $-0,155$ & -0.042 & $-0,008$ \\
\hline & $\mathrm{p}$ & 0,115 & 0,117 & 0.670 & 0,937 \\
\hline \multirow[t]{2}{*}{ SD3 } & $r$ & 0,088 & $-0,045$ & 0.247 & $-0,182$ \\
\hline & $p$ & 0,376 & 0,651 & 0.011 & 0,064 \\
\hline \multirow[t]{2}{*}{ SD4 } & $r$ & $-0,081$ & 0,052 & -0.91 & 0,056 \\
\hline & $p$ & 0,411 & 0,603 & 0.359 & 0,571 \\
\hline \multirow[t]{2}{*}{ SD5 } & $r$ & $-0,042$ & $-0,009$ & -0.076 & 0,021 \\
\hline & $p$ & 0,673 & 0,926 & 0.444 & 0,829 \\
\hline SD Total & r & $-0,070$ & $-0,037$ & -0.005 & $-0,029$ \\
\hline
\end{tabular}


Table 4 Associations between TCl and duration of illness, disease severity, previous glaucoma surgery, treatment response in glaucoma patients (Continued)

\begin{tabular}{|c|c|c|c|c|c|}
\hline & $p$ & 0,481 & 0,706 & 0.958 & 0,771 \\
\hline \multirow[t]{2}{*}{$C 1$} & r & 0,028 & $-0,074$ & -0.014 & $-0,005$ \\
\hline & $p$ & 0,781 & 0,458 & 0.892 & 0,961 \\
\hline \multirow[t]{2}{*}{$C 2$} & r & 0,055 & 0,029 & 0.301 & $-0,094$ \\
\hline & $p$ & 0,581 & 0,770 & 0.002 & 0,342 \\
\hline \multirow[t]{2}{*}{ C3 } & $r$ & $-0,036$ & 0,042 & -0.056 & 0,087 \\
\hline & $p$ & 0,719 & 0,674 & 0.570 & 0,378 \\
\hline \multirow[t]{2}{*}{ C4 } & r & $-0,103$ & 0,018 & -0.203 & 0,226 \\
\hline & $p$ & 0,298 & 0,858 & 0.039 & 0,021 \\
\hline \multirow[t]{2}{*}{ C5 } & $r$ & $-0,084$ & $-0,071$ & -0.201 & $-0,009$ \\
\hline & $p$ & 0,395 & 0,476 & 0.041 & 0,926 \\
\hline \multirow[t]{2}{*}{ C Total } & r & $-0,107$ & 0,015 & -0.100 & 0,134 \\
\hline & $p$ & 0,281 & 0,877 & 0.312 & 0,175 \\
\hline \multirow[t]{2}{*}{ ST1 } & r & 0,005 & $-0,021$ & 0.016 & 0,168 \\
\hline & $p$ & 0,962 & 0,834 & 0.871 & 0,088 \\
\hline \multirow[t]{2}{*}{ ST2 } & $r$ & $-0,158$ & 0,015 & -0.141 & 0,258 \\
\hline & $p$ & 0,109 & 0,880 & 0.154 & 0,008 \\
\hline \multirow[t]{2}{*}{ ST3 } & r & 0,025 & 0,028 & 0.017 & $-0,035$ \\
\hline & $\mathrm{p}$ & 0,800 & 0,774 & 0.865 & 0,723 \\
\hline \multirow[t]{2}{*}{ ST v Total } & r & $-0,043$ & 0,021 & -0.072 & 0,172 \\
\hline & $p$ & 0,662 & 0,834 & 0.469 & 0,081 \\
\hline
\end{tabular}

Exploratory excitability (NS1), Impulsiveness (NS2), Extravagance (NS3), Disorderliness (NS4), Novelty seeking (NS), Anticipatory worry (HA1), Fear of uncertainty (HA2), Shyness (HA3), Fatigability (HA4), Harm avoidance (HA), Sentimentality (RD1), Attachment (RD3), Dependence (RD4), Reward dependence (RD), Persistence (P), Responsibility (SD1), Purposeful (SD2), Resourcefulness (SD3), Self-acceptance (SD4), Congruence (SD5), Self-directedness (SD), Social acceptance (C1), Empathy (C2), Helpfulness (C3), Compassion (C4), Pure-hearted conscience (C5), Cooperativeness (C), Self-forgetful (ST1), Transpersonal identification (ST2), Spiritual acceptance (ST3), Self-transcendence (ST)

As another temperamental dimension, NS was lower in the glaucoma patients than in the controls in our study. NS is characterised by exploration, curiosity, impulsivity and disorganization, and is seen as a tendency to respond to novel stimuli or potential rewards, and actively avoid monotony and punishment [14]. NS is reported as being significantly positively correlated in the personality trait of the extraversion of the Eysenck Personality Questionnaire $[19,24]$. Lower extraversion is reported repetitively in different studies in glaucoma patients [4, 21]. Differences found in the temperament dimensions NS and $\mathrm{HA}$ in our glaucoma patients may reflect their impulsive behavior and automatic decision-making behavior decrease, whereas fearfulness and social inhibition become more pronounced than in the controls.

PS was significantly lower in the glaucoma patients than the control subjects in our study. Persistence is defined as a tendency to persevere in behaviors implicated with reward or relief for punishments [14]. A negative correlation between the harm avoidance and persistence dimensions were demonstrated with a metaanalysis conducted by Miettunen et al. [25] Increased HA scores in glaucoma patients may affect the persistence dimension in our study according to the literature [25].

Character is referred to as a self-concept, and is affected by life experiences and susceptible to learning. Thus, becoming more flexible and thereby configuring individual differences in goals and values. However, the temperament dimensions of personality are defined as being of genetic and biologic structure [17]. Character is defined by three components; SD, C and ST. [17] C was compared between the patients and controls, and there was no difference. However, the glaucoma patients had significantly higher scores than the controls in SD. The higher SD scores reported that increased coherence of personality or 'maturity', protected individuals from depression [26]. This finding was also replicated by Cloninger et al. [26] and to cope with having a chronic illness this component may be elevated in patients. ST is defined as a character trait associated with spirituality by Cloninger et al. [14, 17] When comparing ST, the patients with glaucoma had significantly lower scores than the controls. The lower ST in glaucoma patients may lead them away from 
spirituality; making them more realistic than the rest of the population.

There was no relationship between the disease duration and temperament with the character dimensions in the current study. Personality is generally accepted as a stable structure, and according to Cloninger's model is thought to have a strong long-term stability. Our findings may not support the hypothesis that chronic diseases may lead to personality change in different ways, according to Cloninger's model. As supported by other studies in the literature, characteristic personality profiles in patients can facilitate the occurrence of disease in susceptible individuals $[10,13]$.

There was no difference in the personality dimension between men and women according to some studies [4]. Mabuchi et al. [5] investigated personality in glaucoma patients by using the NEO-FFI, and they revealed the characteristic personality profile (higher neuroticism, lower extraversion, agreeableness, and conscientiousness) occurred in men rather than women. Bubella et al. [13] reported that there was type A behavior in both sexes, but to a higher level in women.

There were some differences in the personality of patients who had previously had glaucoma surgery than with those who had not. HA2, RD1, RD, P and C4 were lower, SD3 and C2 were higher in the patients with glaucoma surgery than those without. These differences may be risk factors that predispose to surgery or that may be developed after the surgical procedure for adaptive reasons.

This study should be regarded as an initial exploration of the personality structure of Turkish POAG patients. However, caution should be exercised when interpreting the findings due to limitations and confounding factors. Firstly, the sample size of this study was relatively small. Secondly, psychiatric symptoms, anxiety, and depression levels of the patients were not further questioned by clinicians, and not included in the study. More studies and different psychological testing methods are required for more conclusive results.

According to Cloninger's model research finding demonstrated that a most common personality profile of chronic disease in aged population patients (different form of chronic pain, ischemic heart disease, chronic obstructive lung disease, hypertension) characterized by prevailing harm avoidance which has been shown to predict the presence of a personality disorder as like our findings [27-31]. This patients could benefit from the measurement of personality by the temperament and character inventory and psychological interventions for improved treatment response.

\section{Conclusion}

In conclusion, our findings indicate that significant differences were found between POAG patients and controls for temperament and character personality features (TCI 240); the glaucoma patients had lower scores for the NS, P, ST, and higher scores for the HA and SD dimensions than the controls. It is suggested that personality factors may be closely related to POAG, and that the personality features of patients should be taken into account when treating those with glaucoma.

\section{Abbreviations \\ TCl: Temperament and Character Inventory; HA: Harm avoidance; PS: Persistence; NS: Novelty seeking; RD: Reward dependence; ST: Self-transcendence; C: Cooperativeness; SD: Self-directedness; IOP: Intraocular pressure; POAG: Primary Open-Angle Glaucoma.}

\section{Competing interests}

The authors declare that they have no competing interests.

\section{Acknowledgements}

All authors (HC, VA, SGY, IKO, TK, AY, CD, SOD and HA) contributed conception and design of the study. HC, SGY, TK and AY additionally contributed in acquisition of data. All authors (HC, VA, SGY, IKO, TK, AY, CD, $\mathrm{SOD}$ and $\mathrm{HA}$ ) contributed analysis and interpretation of data. All authors ( $H C, V A, S G Y, I K O, T K, A Y, C D, S O D$ and $H A$ ) read and approved the final manuscript.

\section{Author details}

${ }^{1}$ Department of Ophthalmology, Adnan Menderes University Medical Faculty, Merkez Kampus Kepez Mevkii, 09100 Aytepe, Aydın, Turkey. ${ }^{2}$ Department of Psychiatry, Adnan Menderes University Medical Faculty, Merkez Kampus Kepez Mevkii, 09100 Aytepe, Aydın, Turkey. ${ }^{3}$ Department of Statistic, Adnan Menderes University Medical Faculty, Merkez Kampus Kepez Mevkii, 09100 Aytepe, Aydın, Turkey. ${ }^{4}$ Department of Ophthalmology, Ege University Medical Faculty, Ege Universitesi Tip Fakultesi Hastanesi, 35040 Bornova, Izmir, Turkey. ${ }^{5}$ Department of Ophthalmology, Balıkesir University Medical Faculty, Usak yolu uzeri Cagis yerleskesi, 10145 Balikesir, Turkey.

Received: 30 March 2015 Accepted: 25 September 2015

Published online: 01 October 2015

\section{References}

1. World Health Organization (WHO). The World Health Report1997: Conquering suffering, enriching humanity. Geneva: WHO; 1997. p. 68-9.

2. Kaluza G, Strempel I, Maurer H. Stress reactivity of intraocular pressure after relaxation training in open-angleglaucoma patients. J Behav Med. 1996;19:587-98.

3. Morreale BR, Morreale BD, Geraci G, Pisello F, Sciumè C. Variation of intraocular pressure during endoscopic diagnostic procedures. Minerva Oftalmol. 2012:54:47-52.

4. Kong X, Yan M, Sun X, Xiao Z. Anxiety and Depression are More Prevalent in Primary Angle Closure Glaucoma than in Primary Open-Angle Glaucoma. J Glaucoma. 2013. [Epub ahead of print]

5. Mabuchi F, Yoshimura K, Kashiwagi K, Yamagata Z, Kanba S, lijima H, et al. Risk factors for anxiety and depression in patients with glaucoma. Br J Ophthalmol. 2012;96(6):821-5.

6. Agorastos A, Skevas C, Matthaei M, Otte C, Klemm M, Richard G, et al. Depression, anxiety, and disturbed sleep in glaucoma. J Neuropsychiatry Clin Neurosci. 2013;25(3):205-13.

7. Demours AP. In: Duke-Elder WS, editor. Text-book of ophthalmology. St Louis: Mosby; 1941. p. 3339.

8. Lim MC, Shiba DR, Clark IJ, Kim DY, Styles DE, Brandt JD, et al. Personality type of the glaucoma patient. J Glaucoma. 2007;16(8):649-54.

9. Zimet CN, Berger AS. Emotional factors in primary glaucoma: an evaluation of psychological test data. Psychosom Med. 1960;22:391-9.

10. Pappa C, Hyphantis T, Pappa S, Aspiotis M, Stefaniotou M, Kitsos G, et al. Psychiatric manifestations and personality traits associated with compliance with glaucoma treatment. J Psychosom Res. 2006;61(5):609-17.

11. Scuderi G, Pompili M, Innamorati M, Pasquale N, Pontremolesi S, Erbuto D, et al. Affective temperaments are associated with higher hopelessness and 
perceived disability in patients with open-angle glaucoma. Int J Clin Pract. 2011;65(9):976-84.

12. Igarashi $Y$, Sato E, Ito A, Miyauchi O, Ikejiri M, Hanawa T, et al. Comparison of Yatabe-Guilford personality test results in retinitis pigmentosa and glaucoma patients. Jpn J Ophthalmol. 2003;47:1-5.

13. Bubella RM, Bubella DM, Cillino S. Type a behavior pattern: is it a risk factor for open-angle chronic glaucoma? J Glaucoma. 2014;23(4):199-201.

14. Cloninger CR, Svrakic DM, Przybeck TR. A psychobiological model of temperament and character. Arch Gen Psychiatry. 1993;50(12):975-90.

15. Trull TJ, Durrett CA. Categorical and dimensional models of personality disorder. Annu Rev Clin Psychol. 2005;1:355-80.

16. Hodapp E, Parrish IIRK, Anderson DR. Clinical decisions in glaucoma. St Louis: The CV Mosby; 1993. p. 84-126.

17. Cloninger CR, Przybeck TR, Svrakic DM, Wetzel RD. The Temperament and Character Inventory (TCI): A Guide to Its Development and Use. St. Louis: Center for Psychobiology of Personality, Washington University; 1994.

18. Köse S, Sayar K, Kalelioğlu U, Aydın N, Ak I, Kırpınar I, et al. Turkish version of the Temperament and Character Inventory (TCI): Reliability, validity, and factorial structure. Bull Clin Psychopharmacol. 2004;14(3):107-31.

19. Eysenck HJ, Eysenck SB. Manual of the Eysenck personality questionnaire. London: Hodder and Stoughton; 1975.

20. Jokela M, Keltikangas JL. The association between low socioeconomic status and depressive symptoms depends on temperament and personality traits. Person Individ Differ. 2011;51(3):302-8.

21. Mabuchi F, Yoshimura K, Kashiwagi K, Shioe K, Kanba S, lijima H, et al. Personality assessment based on the five-factor model of personality structure in patients with primary open-angle glaucoma. Jpn J Ophthalmol. 2005:49(1):31-5.

22. Warrian KJ, Spaeth GL, Lankaranian D, Lopes JF, Steinmann WC. The effect of personality on measures of quality of life related to vision in glaucoma patients. Br J Ophthalmol. 2009;93(3):310-5.

23. Erb C, Thiel HJ, Flammer J. The psychology of the glaucoma patient. Curr Opin Ophthalmol. 1998;9:65-70.

24. Gillespie NA, Johnstone SJ, Boyce P, Heath AC, Martin NG. The genetic and environmental relationship between the interpersonal sensitivity measure (IPSM) and the personality dimensions of Eysenck and Cloninger. Pers Individ Diff. 2001;31:1039-51.

25. Miettunen J, Lauronen E, Kantojärvi L, Veijola J, Joukamaa M. Inter-correlations between Cloninger's temperament dimensions- a meta-analysis. Psychiatry Res. 2008;160(1):106-14.

26. Cloninger CR, Svrakic DM, Przybeck TR. Can personality assessment predict future depression? A twelve-month follow-up of 631 subjects. J Affect Disord. 2006;92(1):35-44.

27. Conrad R, Wegener I, Geiser F, Kleiman A. Temperament, character and Personality disorders in chronic pain. Curr Pain Headache Rep. 2013;17(3):318

28. Gustin SM, Burke LA, Peck CC, Murray GM, Henderson LA. Pain and personality: Do individuals with different forms of chronic pain exhibit a MutualPersonality? Pain Pract. 2015. doi:10.1111/papr.12297.

29. Stetkiewicz-Lewandowicz A, Borkowska A, Sobów T. Temperament and character traits measured by Temperament and character inventory (TCI) by Cloninger in patients with ischemic heart disease. Pol Merkur Lekarski. 2014;37(219):159-62.

30. Kahraman H, Orhan FO, Sucakli MH, Ozer A, Koksal N, Sen B. Temperament and character profiles of male COPD patients. J Thorac Dis. 2013;5(4):406-13.

31. Sovio U, King V, Miettunen J, Ek E, Laitinen J, Joukamaa M, et al. Cloninger's Temperament dimensions, socio-economic and lifestyle factors and metabolicsyndrome markers at age 31 years in the Northern Finland Birth Cohort 1966. J Health Psychol. 2007;12(2):371-82.

\section{Submit your next manuscript to BioMed Central and take full advantage of:}

- Convenient online submission

- Thorough peer review

- No space constraints or color figure charges

- Immediate publication on acceptance

- Inclusion in PubMed, CAS, Scopus and Google Scholar

- Research which is freely available for redistribution

Submit your manuscript at www.biomedcentral.com/submit 